\title{
NO REMANSO DO CONTEXTO RIBEIRINHO QUILOMBOLA DA AMAZÔNIA
}

\author{
Maria Barbara da Costa CARDOSO ${ }^{1}$ \\ PPGED/ICED/UFPA \\ barbara.costa@csfx.org.br \\ Salomão Mufarrej HAGE ${ }^{2}$ \\ PPGED/ICED/UFPA \\ salomao_hage@yahoo.com.br
}

Resumo: O estudo focou a dimensão do contexto da comunidade de São João do Médio Itacuruçá, Abaetetuba/PA, na construção identitária dos sujeitos ribeirinhos quilombolas. A realidade se entrelaça entre rios, mata, estradas, memória e história de luta. Objetiva, portanto, provocar discussões pertinentes ao conceito ribeirinho quilombola. Os sujeitos vivem, moram, lutam pela sobrevivência à margem dos rios e igarapés, no entanto, trazem marcas identitárias quilombola. Como se identificam? Ribeirinhos ou quilombolas? Ou ribeirinhos quilombolas? O trabalho foi de cunho qualitativo, com trabalho de campo com aporte em fontes bibliográficas pertinentes à temática, tendo por base livros, dissertações, teses, artigos, sites. Os resultados pontuam a relevância da discussão do conceito ribeirinho quilombola vivenciado no cotidiano desses sujeitos.

Palavras-chave: Identidade-Ribeirinhos Quilombolas. Saberes Sociais $e$ culturais.

Abstract: The study focused on the dimension of the context of the community of St. John's Midfield Itacuruçá, Abaetetuba / PA, in the relevance of the riparian quilombolas subjects' identity construction. The reality intertwines between rivers, woods, roads, memory and stories of struggles. Objective therefore lead discussions

\footnotetext{
${ }^{1}$ Mestre em Educação, linha de pesquisa Currículo e Formação de Professores, pelo PPGED/ ICED/UFPA (2010). Pedagoga (UFPA-2004), Especialista em Coordenação e Trabalhos Pedagógicos (UFPA-2006). Pesquisadora do GEPERUAZ (UFPA) e GEPESEED (UFPA).

${ }^{2}$ Doutorado Sanduíshe pela Universidade de Wisconsin/Madison (1999) e, Doutorado em Educação: Currículo pela Pontifícia Universidade de São Paulo (2000). Mestrado em Educação: Supervisão e Currículo (1995), Graduação em Agronomia (1982) e em Pedagogia (1987), Coordenador e pesquisador do GEPERUAZ.
} 
relevant to the concept riparian quilombola. The subjects live, reside, struggling to survive on the margins of rivers and streams, however, bring identity marks quilombolas. As identify? Riparian or quilombolas? Or riparian quilombolas? The study was a qualitative one, with fieldwork with investments in bibliographical sources relevant to the topic based on books, dissertations, theses, articles, websites. The results punctuate the importance of discussing the concept riparian quilombola experienced in everyday life these subjects.

Keywords: Identity-Riparian Quilombolas. Social and Cultural Knowledge.

\section{Introdução}

Os saberes ribeirinhos quilombolas vêm provocar uma reflexão sobre a riqueza de conhecimentos vivenciados no dia a dia desses sujeitos que, de maneira criativa, manifestam-se com características tipicamente amazônicas.

Em se tratando de sujeito ribeirinho quilombola na Amazônia, podemos descrever o seu perfil como aquele que tem uma especificidade de morar, trabalhar e conviver na inter-relação com os rios, os igapós, os igarapés, a terra, as matas e as florestas: sujeito envolto pela natureza, que, principalmente, sobrevive dos recursos dela extraídos.

O porquê de denominá-los ribeirinho quilombola se dá em razão dessa particularidade vivenciada e assegurada por direito aos moradores remanescentes quilombolas que usufruem, como base, da vida ribeirinha. A compreensão dessa denominação vai além das definições oficiais que dicotomizam os termos (ribeirinhos e quilombolas). $\mathrm{Na}$ vida diária, o morador das comunidades remanescentes quilombolas, que se localizam nos espaços ribeirinhos, interagem nessa especificidade de vida e saber, que se faz presente na memória dos moradores quilombolas mais antigos da comunidade de São João no Médio Itacuruçá.

A vida ribeirinha quilombola é fortemente movida pelo trabalho, o que não é o mais importante. Muitos valores são fundamentais para a comunidade: um deles é viver e conviver bem na família e na comunidade, em uma relação de saber:

Toda relação com o saber, enquanto relação de um sujeito com seu mundo é relação com o mundo e com uma forma de apropriação do mundo: toda relação com o saber apresenta 
uma dimensão epistêmica. Mas qualquer relação com o saber comporta também uma dimensão de identidade: aprender faz sentido por referência à história do sujeito, às suas expectativas, às suas referências, à sua concepção da vida, às suas relações com os outros, à imagem que tem de si e à que quer dá de si aos outros (CHARLOT, 2000, p.72).

O saber se entrelaça e faz parte de um grande emaranhado com o afetivo, o social, o cultural, o histórico e o político, possibilitando uma identidade própria, preservada pela perpetuação de seus costumes e de suas tradições, ao longo dos séculos, e pela transmissão destes pelos mais velhos aos mais novos. Os saberes estão relacionados também com a concepção de vida, de sociedade e de relações humanas. Nessas relações, está a educação que não se faz apenas nos espaços escolares, mas acontece nos processos de trabalho, de organizações políticas e culturais.

Os saberes sociais e culturais dos sujeitos ribeirinhos quilombolas trazem marcas identitárias localmente amazônicas que emergem devido à necessidade de subsistência de vida. Seus instrumentos de trabalho advêm, na maior parte, da própria natureza, e criativamente são produzidos por estes sujeitos. Ex.: matapi, tipiti, paneiro, vassoura, cestos, peconha etc.

Os saberes dos sujeitos ribeirinhos quilombolas se manifestam em seus afazeres diários inseridos na realidade dos rios, igarapés, estradas e ramais, com fortes traços vividos entre os rios, território, identidade e luta por uma vida digna e pela conquista de espaço social.

\section{A identidade ribeirinho quilombola}

A discussão do termo ribeirinho quilombola causa estranheza e questionamento. Por que da expressão ribeirinho quilombola? Usar este termo não diminui a força do ser quilombola? Estas foram algumas das indagações que ouvimos ao longo da nossa pesquisa. No entanto, ao adentrarmos ao contexto da comunidade de São João do Médio Itacuruçá, por meio de conversas com os ribeirinhos quilombolas, fomos aprendendo que o cotidiano, o saber que se faz na história, no suor do trabalho, perpassa impreterivelmente a descrição conceitual. Pois, tornase tão subjetivo aos próprios sujeitos que autores externos (no caso, nós pesquisadores) não conseguimos captar a dimensão da força que perfaz a

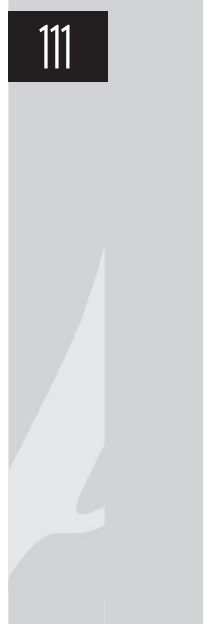


denominação do ser ribeirinho quilombola. Na fala de dona Raimunda Celesmina Costa, ribeirinha quilombola:

Há muito vivo aqui. Meus pais e avós viveram aqui. $A$ gente se sente comunidade do rio Itacuruçá. Antes, a gente vinha só pelo rio, viajava e trabalhava como ribeirinho, mas quando lembro o povo de antes, eles eram negros, meus pais. Eu sempre lembro de algumas histórias deles, dos quilombolas (COSTA, 2011).

Na expressão de Dona Celé, assim conhecida na comunidade, compreende-se que o termo ribeirinho quilombola se fortalece na história e na vida de seu povo.

Ao se buscar a fundamentação conceitual de ser ribeirinho quilombola, nos levaram a compreender a ressignificação da identidade desta comunidade. Traços marcantes ribeirinhos se entrelaçam às marcas identitárias de quilombolas. A vida cotidiana nos trás leitura do buiar ${ }^{3}$ das águas, do gapuiar ${ }^{4}$ em busca do melhor camarão, da puqueca (isca) usada no matapi na pesca do camarão, os contos e causos sobre assombrações, as benzições etc, enfim, saberes que permeiam a vida dos ribeirinhos quilombolas de Itacuruçá.

Ao buscar conceitos para se ter compreensão dos sujeitos que trazem especificidades de vida, no nosso caso, os ribeirinhos quilombolas, Cunha e Almeida (2001, p. 192) salientam que os conceitos apontam para a formação de sujeitos no saber político, por meio de novas práticas de vida. Ou seja, os autores afirmam que, com o encontro dos conceitos da cidade com o "outro", sujeitos munidos de especificidade, novos termos são criados para que este outro tome alguma forma e, em alguns casos, este termo garante ao outro uma posição política interessante, conferindolhe direitos sui generis. Neste sentido, percebemos que termos novos são criados para classificar este "outro", para se justificar a significação conceitual. No entanto, acrescentam os autores, que com o passar do tempo, e dependendo da conveniência, estes termos são ou não "aceitos".

${ }^{3}$ buiar (boiar) - flutuar sob às águas, andar a tona de água; sobrenadar;

${ }^{4}$ gapuiar - (guar igapiar) - Esgotar um igarapé ou igapó, para deixar o camarão ou peixe em seco; Apanhar camarões nos pequenos igarapés. 
A busca de identidade requer um reconhecimento social. No caso dos ribeirinhos quilombolas, é possível verificar que o termo vem sendo habilitado por novos atores sociais, assim como vem transformando-se em uma bandeira política para os seus componentes, visto que, como será comentado em um momento posterior, seus direitos, inclusive territoriais, são garantidos em função de suas lutas, seus saberes e sua história.

$\mathrm{Na}$ vivência do contexto da comunidade São João do Médio Itacuruçá, afirma-se que esta comunidade pode ser chamada também de população tradicional, na medida em que ainda preserva alguns dos valores cultivados nas culturas ribeirinhas quilombolas. Essa população outrora sobreviveu dos recursos naturais locais e tinha as suas escolhas de reprodução social fortemente influenciada pelo rio Itacuruçá.

Arruda (1999, p.79-80) frisa que populações tradicionais são aquelas que apresentam um modelo de ocupação do espaço e uso dos recursos naturais voltados principalmente para a subsistência, com fraca articulação com o mercado, baseado em uso intensivo de mão de obra familiar, tecnologias de baixo impacto, derivadas de conhecimentos patrimoniais e, normalmente, de base sustentável.

Arruda (1999) nos traz a situação de fragilidade em que essas populações tradicionais se encontram, principalmente, na busca de sustentabilidade por meio do extrativismo e da exploração dos recursos naturais, como a comunidade de São João, que busca o trabalho no manejo do açaí, na produção de telhas e tijolos, no cultivo da mandioca e em outras produções.

Referimo-nos aos saberes dos sujeitos ribeirinhos quilombolas da comunidade de São João do Médio Itacuruçá, cuja riqueza consiste na experiência de vida e no trabalho de subsistência, que marcam a identidade desses sujeitos.

A luta da comunidade é para garantir o uso (ou a preservação) das terras, dos rios, da mata, desencadeando discussões e ações para assegurar condições de vida digna para todos os ribeirinhos quilombolas. Lutam por uma educação de reconhecimento da subjetividade, da diversidade, e dos saberes de seus sujeitos. 


\section{Entre rio e terra: a comunidade de São João do Médio Itacuruçá}

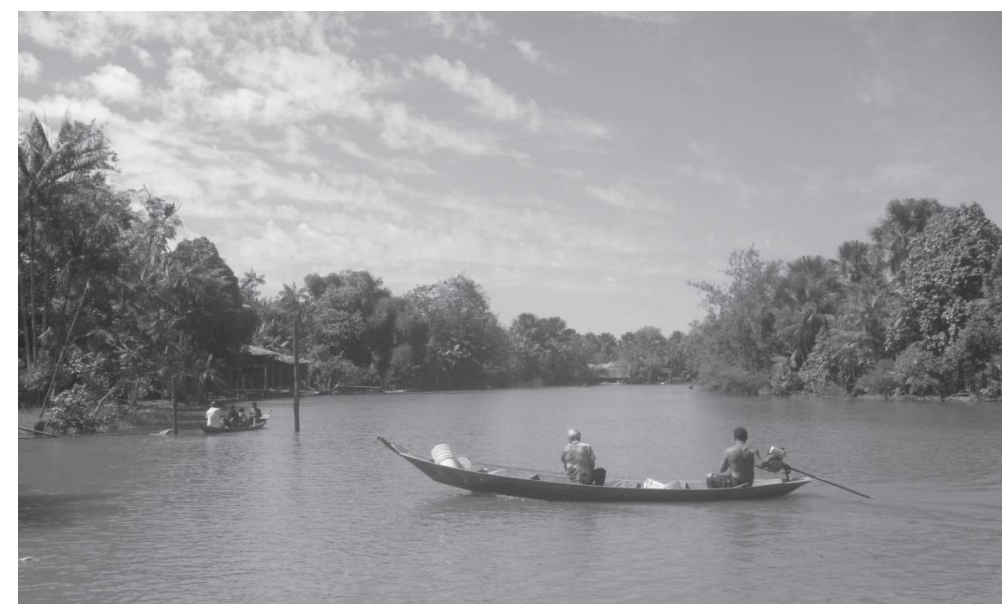

Foto 1 - Ribeirinhos Quilombolas em trajeto no Rio Itacuruçá (Autor: Salatiel, 2011)

Foto 1 - Rio Itacuruçá - Comunidade São João Batista

(Autora CARDOSO, 2010)

No remanso das águas da comunidade de remanescentes quilombolas (Foto1), apresentamos a comunidade São João do Médio Itacuruçá. Como quilombola, esta comunidade foi apurada na demarcação administrativa por meio do processo $\mathrm{n}^{\mathrm{o}}$. 2001/274.554 e está localizada no município de Abaetetuba, com área total de 11.458, 5310 hectares (ITERPA - Governo do Estado do Pará, 2002). Ressaltamos que esta área corresponde a todo território (Baixo, Médio e Alto) Itacuruçá.

No município de Abaetetuba somam-se até 2010, oito comunidades remanescentes de quilombos (Acaraqui, Tauerá-Açu, Arapapu, Arapapuzinho, Genipaúba, Alto, Médio e Baixo Itacuruçá). Nosso foco de análise destaca a do Médio Itacuruçá, que, como as demais comunidades, foi reconhecida por titulação pelo Instituto de Terras do Pará (ITERPA) em 2002.

A Geografia do rio Itacuruçá, conforme informações de moradores, sofreu muitas modificações devido à exploração das matas, do rio e da própria terra. 
Há muito tempo atrás, aqui era apenas o rio e a floresta. Isto ainda prevalece, mas, com a interferência do ser humano, tudo vai se modificando, tornando-se involutariamente dominado pelas transformações que o homem exerce. Antes dessa escola (referindo-se à Escola Manoel P. Ferreira), a gente tinha outra no barracão. A gente remava muito até chegar aqui. (COUTO, 2011).

Para o Senhor Humberto Couto, na representatividade da fala dos ribeirinhos quilombolas, o rio se apresenta como importante centro produtivo para a comunidade. Negros e índios que habitavam às suas margens produziam alimentos só para consumo próprio e de suas famílias. Com o aumento do número de habitantes, sentiram a necessidade de escoar esta produção.

A comunidade de São João do rio Itacuruçá há dez anos possuía apenas o rio como via de ligação com a cidade de Abaetetuba, mas, devido à expansão e à transformação do comércio, logo foi surgindo o ramal do Médio Itacuruçá, estrada de terra, sem pavimentação asfáltica (o que a torna quase inacessível no período chuvoso). A comunidade, desde 2006, começou a ter acesso à energia elétrica.

Podemos ilustrar a beleza natural do Médio Itacuruçá na relação rio-terra-mata da Amazônia, principalmente no eixo central da comunidade, onde se presencia o descaminho do rio que dá acesso às comunidades vizinhas (Baixo e Alto Itacuruçá). Fazem parte também deste espaço as pequenas embarcações (barcos, canoas, rabetas e rabudo) que por ali transitam, fazendo transporte de pessoas e de produtos para vendas. Pelo acesso do ramal, vê-se que as áreas de matas estão sendo derrubadas e substituídas por plantações de dendê, causando, assim, uma visível destruição ambiental e humana.

Esta realidade denuncia as marcas identitárias da exclusão, ao mesmo tempo em que essa área é castigada pelo descaso humano de preservação e de manutenção: nesta localidade está patente a indiferença por parte do poder público (Foto 3). Por estar afastada da cidade, sua população carece de bens e, principalmente, de atendimento médico e educacional. Em caso de doença, as famílias têm de se deslocar aos municípios mais próximos, pois não há posto de saúde no local. 


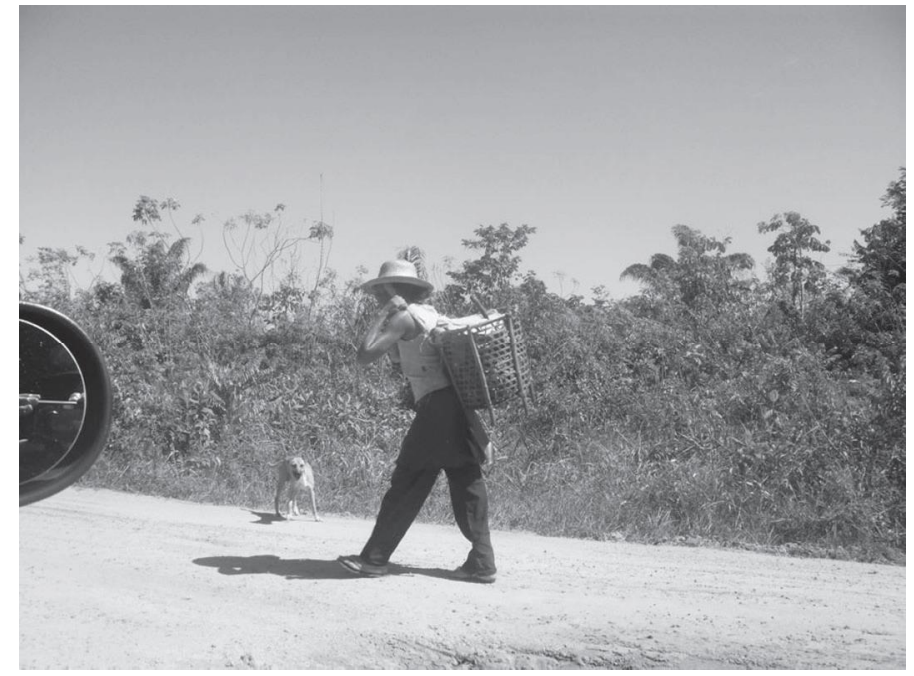

Foto 2. Dona Celé, Agricultora quilombola do Médio Itacuruçá

(Autor Salatiel-2011)

Dona Raimunda Celesmina Pinheiro, conhecida como dona Celé, 73 anos, é agricultora, trabalha com o cultivo da mandioca. Sua jornada começa às 5 horas da manhã e se estende até "tardinha".

Além das dificuldades na produção das olarias e da farinha, do plantio da mandioca e do manejo do açaí os ribeirinhos quilombolas ainda são penalizados pela ausência de infraestrutura mínima, presente em qualquer comunidade urbana. A relação campo-cidade é dicotômica, divergindo em muitos fatores, principalmente na comercialização de seus produtos. Os ribeirinhos quilombolas negociam seus produtos (cerâmicas, farinha, açaí) por preços abaixo do custo, fazendo-se visível a figura do atravessador - aquele que compra o produto na fonte por um preço baixo e renegocia obtendo lucros. É uma situação de exploração e domínio vivenciada pela comunidade.

\section{O sujeito ribeirinho quilombola no Médio Itacuruçá}

A comunidade de São João do Médio Itacuruçá vive o cotidiano ribeirinho quilombola. Segundo Furtado e Melo (1993), o termo ribeirinho é usado na Amazônia para designar as populações humanas 
que moram à margem dos rios e que vivem da extração e do manejo de recursos florestais, da pesca e da agricultura familiar. Os ribeirinhos quilombolas amazônicos, por sua vez, são representados, principalmente, por populações que vivem do manejo do açaí, da pesca nas várzeas e rios de forma artesanal, da produção da farinha e, atualmente, o destaque são as olarias.

Ribeirinhos quilombolas, assim referidos por apresentarem uma especificidade de vida e de fato, isto é, permeados pela própria natureza e na luta sustentável por melhores condições de vida, trazem a marca de "ribeirinhos", concomitantemente, "quilombolas" por trazerem raízes históricas e de reconhecimento de terras ocupadas por seus antecedentes.

A identidade ribeirinho quilombola se faz em uma história de luta, de resistência marcada por uma realidade envolta pela natureza, pelos rios, pela terra, pelo trabalho, em uma região caracteristicamente amazônica. Seu Big (Humberto Couto) nos fala por meio de suas memórias:

Olhando, assim, podemos ver que o rio Itacuruçá está sempre
em momentos religiosos, às vezes são católicos, às vezes são
protestantes, outras festas e nunca sumiu esse modo de ser
de nossa comunidade. Para os negros e indios que moravam
aqui, tudo o que produziam era mantido em suas casas. Mas
com a habitação aumentando, tudo foi modificando, todos
sentiram a necessidade de escoamento do que produziam, e a
falta de alguns utensílios para eles. A gente precisa de novos
instrumentos para o trabalho. (COUTO,H, 2011).

A história quilombola no Médio Itacuruçá está vulnerável ao esquecimento. Poucos moradores, como o Senhor Humberto Carvalho do Couto, trabalhador e proprietário de olaria, 81 anos, têm a preocupação de contar histórias antigas para os filhos e jovens da comunidade.

Vamos nos reportar ao período colonial em que milhares de negros escravizados eram enviados das costas do Golfo de Guiné, dos litorais de Angola e Moçambique, para labutar na lavoura canavieira e em outras atividades e, assim, passavam a fazer parte da sociedade constituída por negros escravizados. Dessa relação, emergiram dois fenômenos decorrentes do sistema escravista, quais sejam a fuga e a organização de quilombos. 
Envidaram esforços nas fugas para lugares mais longínquos, de difícil acesso, alimentando o fenômeno quilombola durante todo o período escravista. O excesso de trabalho, os castigos e os maus-tratos, e o trabalho excedente forçavam os trabalhadores escravizados ao abandono do roçado, fugindo para as matas em desesperada defesa da própria vida.

Segundo Maestri (1988, p. 130), os trabalhadores escravizados eram movidos para a fuga pela busca de liberdade e autonomia no trabalho. Essa autonomia se dava na ação de fuga em busca de uma terra desocupada que propiciasse a organização da economia agrícola de subsistência, preferencialmente de forma coletiva.

O quilombo podia gerar-se quase naturalmente. Depois de instalado, crescia e tomava consistência à medida que recebia novos indivíduos. A fuga e a organização quilombola acompanharam todo o período escravista.

Mesmo com a libertação, pouco mudou na vida dos ex-escravos no que concerne às condições materiais de existência, não raro parecidas ao do cativeiro. No entanto, juridicamente, os trabalhadores escravizados passaram a ter autonomia sobre seu labor, não necessitando mais da fuga para dominarem sua força de trabalho. Assim sendo, o quilombo deixou de existir como fenômeno sociológico histórico. Passamos a ter no Brasil, no mundo rural, comunidades negras, de diferentes origens, lutando pelo controle da terra e pela venda de sua força de trabalho.

Algumas comunidades negras, originárias dos antigos quilombos que haviam escapado à repressão, continuaram no espaço geográfico que dominavam; outras foram encurraladas pela expansão da produção agrícola-pastoril mercantil.

Nas comunidades negras rurais, os trabalhadores passaram a enfrentar problemas comuns. Para Maestri (1988, p.130), os trabalhadores negros rurais viveram como meeiros, moradores, posseiros, intrusos etc., não chegando a vislumbrar a possibilidade da legalização da posse das terras que exploravam asseguradas pela lei, chamada Lei de Terras, de 1850, que proibiu a entrega gratuita de terra. Esta ação impediu a ampliação da classe de camponeses proprietários, pois isto desviaria o homem livre pobre da necessidade de vender sua força de trabalho a vil preço nos latifúndios. 
Neste sentido, as terras que escaparam da apropriação passaram a integrar o patrimônio da União, dos estados e dos municípios, na categoria de terras devolutas. No entanto, embora se entendesse que o trabalhador negro do campo tinha iguais possibilidades de compra ou de posse da terra, o acesso desse trabalhador era dificultado porque dispunha de pouco dinheiro e não sabia lidar com a burocracia para defender o seu direito.

Diversos fatores se faziam empecilho para organização dos trabalhadores negros rurais: a baixa renda monetária, a falta de representação política, a ausência de recursos para financiar o plantio, a carência de assistência técnica, entre outros. Pode-se afirmar que o capital foi o grande desestabilizador dessas comunidades. Em algumas, os trabalhadores tiveram suas plantações destruídas, águas envenenadas, e, não raro, os líderes assassinados.

Segundo Anjos (2006), atualmente, ao se definir a importância da terra para as comunidades negras contemporânea, assume-se o resgate de uma identidade:

O território é uma condição essencial porque define o grupo humano que o ocupa e justifica sua localização em determinado espaço. Portanto, a terra, o terreiro não significam apenas uma dimensão física, mas antes de tudo é um espaço comum, ancestral, de todos que têm o registro da história, da experiência pessoal e coletiva do seu povo, enfim, uma instância do trabalho concreto e das vivencias do passado e do presente (ANJOS, 2006, p. 49).

A própria terra tem um sentido especial a todo homem e a toda mulher do campo, sejam eles de origem africana, europeia ou nativa. Não deve ser apenas tomada como forma física, mas também como espaço das relações sociais, como reveladora das estratégias de sobrevivência, de uma cultura própria, de uma identidade, como direito à preservação de uma cultura e organização social específica.

Salomão da Costa Santos, quilombola do Médio Itacuruçá declara:

Os ribeirinhos de hoje já são diferentes. Muitos vivem e moram à beira dos rios, trabalhando na roça, olaria $e$ açaizal, produzindo farinha, telha, tijolo, matapi, paneiro, 
faz criação de muitos bichos, mas outros já vão mais pra cidade e lá estudam e trabalham também, sempre voltam. E hoje algumas casas são feitas de tábua e coberta de telha. Outras são de alvenaria. Aqui ainda se bebe mingau na cuia. Os meios de transportes são as rabetas, os barcos, cascos, canoas, o mais rápido é o rabudo. Com a energia temos a televisão e o computador. Ser quilombola, nós somos sim. Nós temos título de terra. Ainda não conseguimos nossos direitos, mas estamos sempre sabendo o que se passa (SANTOS, S, 2011).

Percebe-se, portanto, uma identidade ribeirinha quilombola se auto afirmando pela busca de seus direitos à terra, ao trabalho, à natureza, aos seus saberes.

A identidade ribeirinha quilombola se faz por meio dos momentos comunitários, dos saberes, ensinados de pai para filho, na luta do trabalho para a sobrevivência e um viver melhor:

A gente vive bem com todos, mesmo que tenha vindo outras pessoas. Somos muitos aparentados uns dos outros. A gente se reúne quando ver que outros querem explorar a nossa produção e aí a gente sente falta de alguns benefícios, a gente precisa se juntar e ver o que fazer (SANTOS, S, 2011).

Esta insistência de se viver em comunidade, compartilhando e buscando conviver com todos numa relação harmoniosa é marcante em Itacuruçá. Muitas vezes, nas entrevistas, começávamos a conversar com um dos sujeitos e de repente presenciávamos a chegada de outros que, aos poucos, ia se introduzindo na conversa. Então, deduzíamos que a história não é feita só por um, mas pela comunidade.

$\mathrm{Na}$ comunidade, muitos moradores fazem comentários de que ser quilombola é algo que concedeu privilégios, entre eles o de poderem participar de muitos programas do governo: o título de terra foi um. No entanto, em relação à memória de vida, às suas raízes quilombolas, que são a cultura e as tradições transmitidas pelos mais velhos, nos dias de hoje, já estão quase perdidas, principalmente pela morte dos membros mais velhos da comunidade. Junte-se a isso a desmotivação das novas gerações de dar continuidade ao legado cultural dos mais 
antigos, por ser este, em quase sua totalidade, transmitido oralmente. Como nos fala Susana Pinheiro da Costa, quilombola e professora na comunidade:

Aqui mesmo quem sabia de nossas histórias eram os mais velhos. A gente só sabe que somos quilombolas porque falam. Mas não tenho nenhum registro mesmo. Outra coisa: Aqui mesmo nem se comenta muito, só quando a gente tem algum direito a receber. Mas era bom se a gente conhecesse nossa história (COSTA, S, 2011).

Neste discurso, é possível observar a memória do trabalho tradicional quilombola, que se faz na comunidade por meio da atividade do cultivo da mandioca, do cuidado com o rio, do árduo trabalho das olarias, da tarefa de amassar, enfurnar e empilhar os tijolos: são tarefas fortemente marcadas por algumas identidades sociais historicamente construídas. Dessa forma, as pessoas se reconhecem, identificam-se e são diferenciadas conforme as características étnicas que se assinalam e se fazem presente nas relações de parentesco com o quilombo. Concomitante à memória do quilombo, essa memória coletiva também é negada por meio da interação entre os membros.

Percebemos que, apesar de os sujeitos ribeirinhos quilombolas terem demonstrado a existência de conflitos em relação à própria identidade, manifestaram, ainda que inconscientemente, algumas situações que evidenciaram a existência de processos que contribuem para a constituição de sua identidade quilombola. Nessas relações aparecem as marcas identitárias da etnia: a de um discurso social determinado de diferenciação cultural, pois eles são eleitos, conforme a criação dos termos de inclusão e de exclusão socialmente construído.

Hoje, a comunidade ribeirinha quilombola do Médio Itacuruçá é ocupada pelas famílias dos parentes, dos descendentes dos casais fundadores. Todo esse espaço é definido pela descendência e pelas trocas matrimoniais.

O ribeirinho quilombola busca firmar sua identidade na convivência comunitária com os seus pares, seja nas reuniões da comunidade, nas instituições religiosas ou nas associações: ARQUIA (Associação dos Remanescentes Quilombolas de Abaetetuba), COOPROABA (Cooperativa dos Produtores de Artefatos de 
Abaetetuba), MALUNGU (Associação Regional dos Remanescentes Quilombolas do Pará).

A Organização política da comunidade apresenta caráter instrumental para que as famílias ribeirinhas quilombolas se apoderem e dominem os conhecimentos, as habilidades e as atitudes, que lhes permitam assumir a responsabilidade do seu próprio desenvolvimento de forma autônoma; e de gestão, de maneira a fazer valer sua autodependência. As Associações buscam principalmente a afirmação de pertencimento de identidade negra e de território de remanescentes quilombolas.

Percebemos que os movimentos de mobilização e de desmobilização ocorrem continuamente, e se dão, por vezes, por conta dos preconceitos gerados pelos estigmas existentes no interior do grupo e sofridos por eles. O modo como a sociedade concebe indivíduos estigmatizados, o encontro entre estes grupos e o meio social abrangente colocam em evidência o efeito do estigma, fator este que provoca uma situação angustiante para todos os envolvidos na comunidade.

Por outro lado, a afirmação da identidade ribeirinha quilombola, a valorização da ancestralidade africana na memória viva do passado, aqui posta anteriormente por Seu Big, e a valorização das culturas religiosas e saberes são elementos fundamentais que orientam as inter-relações culturais e o diálogo na comunidade ribeirinha quilombola de Itacuruçá.

Segundo Munanga:

O resgate da memória coletiva e da história da comunidade negra não interessam apenas aos alunos de ascendência negra. Interessam também aos alunos de outras ascendências étnicas, principalmente branca, pois ao receber uma educação envenenada pelos preconceitos, eles também tiveram suas estruturas psíquicas afetadas. Além disso, essa memória não pertence somente aos negros. Ela pertence a todos, tendo em vista que a cultura da qual nos alimentamos quotidianamente é fruto de todos os segmentos étnicos que, apesar das condições desiguais nas quais se desenvolveram, contribuíram cada um de seu modo na formação da riqueza econômica e social e da identidade nacional (MUNANGA, 2001, p. 9).

Salientamos que a comunidade apresenta raízes, memórias quilombolas de identidade negra, por isso Gomes (2003) a entende como 
"uma construção social, histórica, cultural e plural. Implica a construção do olhar de um grupo étnico-racial ou de sujeitos que pertencem a um mesmo grupo étnico-racial sobre si mesmo, a partir da relação com o outro". Segundo a autora, "construir uma identidade negra positiva em uma sociedade que historicamente ensina ao negro, desde muito cedo, que para ser aceito é preciso negar-se a si mesmo, é um desafio enfrentado pelos negros brasileiros" (GOMES, p.171).

Neste enfrentamento, principalmente, o de vencer o silêncio e a invisibilidade em relação à questão étnica, muitos desafios são postos à comunidade. Um deles é em relação à religião. Presencia-se o catolicismo na vida de poucos comunitários que têm como devoção Nossa Senhora do Pau Podre. Este grupo se reúne semanalmente para as reuniões da Igreja, e, nos finais de semana, para o catecismo às crianças.

É importante também pontuar que a comunidade ribeirinha quilombola tem predomínio da religião Evangélica. Muitas famílias protestantes se unem para a realização de atividades desenvolvidas na Igreja. Em suas casas cotidianamente é vivenciada a prática religiosa. Em visitas, nos apercebemos dessa realidade marcante. Ouvem pregações e música gospel em família durante os seus afazeres domésticos.

Segundo Salatiel Costa Santos, quilombola:

Nós temos um forte grupo de jovens que desenvolvem atividades na comunidade. Levamos a Palavra do Senhor. As crianças precisam de educação religiosa para respeitar os mais velhos, respeitar melhor a comunidade. Isto nos une muito. Formamos uma só família. Isto nos ajuda na comunidade quilombola (SANTOS, S. C, 2011).

O terreiro de umbanda se faz presente, mas pouco se manifesta na comunidade. Suas atividades são desenvolvidas à noite, sendo visitadas por outras pessoas que vêm de outras localidades para as "benzições".

A gente sabe que o terreiro é uma herança negra. Mas como somos protestantes, a gente não se envolve. Eles fazem os seus trabalhos sem incomodar a gente. E não é todas as noites. Quando menos a gente vê, ouve os tambores. Fica lá do outro lado (COUTO, H., 2011). 
Em relação ao fator religioso, destaca-se a predominância da religião protestante, embora as demais religiões busquem seu espaço nas organizações e manifestações na comunidade. No entanto, há proximidade de seus sujeitos pela necessidade da organização do trabalho comunitário.

Desse modo, o trabalho e a religião, como aspecto cultural dos ribeirinhos quilombolas, tornam-se um dos elementos fundantes de compreensão do mundo em que vivem e do lugar no qual estão inseridos.

Referente a este aspecto híbrido da cultura, são válidas as considerações de Homi Bhaba (1998), que tecendo uma análise da cultura no contexto pós-colonial, define-as como culturas marcadas por histórias de deslocamentos de espaços e origens. $\mathrm{O}$ autor frisa que tais deslocamentos ocorreram tanto na experiência da escravidão como na experiência da diáspora migratórias das metrópoles para as colônias e das colônias para as metrópoles.

A comunidade ribeirinha quilombola, uma vez que nela ocorrem esses deslocamentos espaço-culturais, em que acontecem trocas culturais, não se caracteriza como um reduto fechado nem como guardiã de suas tradições.

O trabalho fronteiriço da cultura exige um encontro com "novo" que não seja parte do continuum de passado $e$ presente. Ele cria uma idéia do novo como ato insurgente de tradução cultural. Essa arte não apenas retoma o passado como causa social ou precedente estético; ela renova o passado, refigurando-o como um "entre lugar" contingente, que inova e interrompe a atuação do presente. O passadopresente torna-se parte da necessidade, e não da nostalgia, de viver (BHABHA, 1998, p.29).

Este trabalho comunitário, com raízes do passado, mas com dinamicidade do presente, vivencia a reciprocidade e a sociabilidade dentro desses territórios e rios, fazendo com que os objetos individuais sejam ao mesmo tempo coletivos, uma vez que ocorre o empréstimo de matérias de trabalho, utensílios de casa, e até empréstimo de roçados e retiros, apresentando-se como instrumentos para construção do território e da vida ribeirinha que compõem a comunidade. O fator comunitário do trabalho é relevante nos remanescentes quilombolas, como casa de 
farinha, galpão para fazer utensílios domésticos e/ou artesanato, canoas, rabetas, campo de futebol, igreja etc., e que, de fato, assumem papel importante na estrutura da geografia quilombola.

\section{Conclusão}

Provocar discussão acerca da identidade quilombola e de seu processo de empoderamento - aqui entendido como um processo que fortalece a autoconfiança dos ribeirinhos quilombolas em relação ao seu reconhecimento e identidade de ser, com intuito de capacitá-los para a articulação de seus interesses e para a participação na sociedade, além de lhes facilitar o acesso aos recursos sociais disponíveis e o controle sobre estes - é ação necessária, na perspectiva de enriquecer e apontar novos caminhos que estimulem o resgate da memória da comunidade, as práticas sociais, religiosos e as políticas públicas.

O sujeito ribeirinho quilombola nos mostra que sua identidade está incrustada em aspectos interligados à sua história, aos seus saberes, ao trabalho, à sua religião.

Não nos cabe aqui definirmos o ser ribeirinho quilombola com base em nossa visão, mas termos a sensibilidade de compreender a subjetividade que se faz presente na busca de sua auto-afirmação, que ao longo dos anos foi reprimida pela história dos que detinham o poder aquisitivo e de persuasão.

Portanto, o combate ao racismo e a construção de práticas socioeducativas que reconheçam e valorizem as manifestações das diferenças culturais é um desafio constante para os ribeirinhos quilombolas.

\section{REFERÊNCIAS}

ANJOS, Rafael S. A. dos. Quilombolas: tradições e cultura da resistência. São Paulo: Aori Comunicação, 2006.

ARRUDA, Rinaldo "Populações tradicionais" e a proteção de recursos naturais em unidade de conservação. Ambientes \& Sociedade, Ano II, n. 5,1999. 
ARRUTI, José Maurício. Mocambo: antropologia e história do processo de formação quilombola. Bauru: EDUSC, 2006.

BHABHA, Homi. O local da Cultura. Belo Horizente: UFMG, 1988.

CHARLOT, Bernard. Da relação com o saber: elementos para uma teoria. Porto Alegre: ArtMed, 2000.

COSTA, Celino dos Passos. Entrevista concedida a Maria Barbara da C. Cardoso. Médio Itacuruçá, 2011.

COSTA, Suzana Pinheiro. Entrevista concedida a Maria Barbara da C. Cardoso. Médio Itacuruçá, 2011.

COUTO, Humberto Carvalho. Entrevista concedida a Maria Barbara da C. Cardoso. Médio Itacuruçá, 2011.

CUNHA, Manoela Carneiro da; ALMEIDA, Mauro W. B. Populações Tradicionais e conservação ambiental. In: CAPOBIANCO, João Paulo Ribeiro et al. Biodiversidade na Amazônia brasileira: avaliações e ações prioritárias para a conservação, uso sustentável e repartição de benefícios. São Paulo: Instituto Sócio Ambiental, 2001.

GOMES, N. L.; SILVA, O. B. Experiências étnico-culturais para a formação de professores. Belo Horizonte: Autêntica, 2002.

MAESTRI, Mário. A servidão negra. Porto Alegre: Mercado Aberto,1988.

MUNANGA, Kabengele. (Org.) Superando o Racismo na Escola. $3^{a}$ ed. Brasília: Ministério da Educação/Secretaria da Educação Fundamental, 2001.

PINHEIRO, Raimunda Celesmina. Entrevista concedida a Maria Barbara da C. Cardoso. Médio Itacuruçá, 2011.

ROCHA, Rosildo Brandão. Entrevista concedida a Maria Barbara da C. Cardoso. Médio Itacuruçá, 2011.

SANTOS, Salomão da Costa. Entrevista concedida a Maria Barbara da C. Cardoso. Médio Itacuruçá, 2011.

SANTOS, Salatiel da Costa. Entrevista concedida a Maria Barbara da C. Cardoso. Médio Itacuruçá, 2011. 